Section 4

Change management in e-health 



\title{
Do healthcare professionals use IT?
}

\author{
Ton AM Spil, Roel W Schuring and Margreet B Michel-Verkerke
}

\section{Introduction}

Information technology (IT) is emerging in healthcare, ${ }^{1}$ but successfully implementing information systems in healthcare organizations appears to be a difficult task. ${ }^{2}$ Information Technology is seen as an enabler of change in healthcare organizations. ${ }^{3}$ Southon ${ }^{4}$ suggests that (information) technology adoption decisions in healthcare are complex because of the uncertainty of benefits and the rate of change of technology. ${ }^{5}$ This book tries to unravel this complexity, and in this chapter we look at successful change management from a user perspective. Determinants on other levels may also be important, such as the level of project management, the level of the organization or even the level of the society. ${ }^{6}$ On a system level, reimbursement structures, regulations and the existence of standards may have an explanatory role. On an organization level, the previous strategic choices, strategic priorities, size and location of the organization, and many other factors may play a role. Similarly, Kimberly and Evanisko discuss such factors. ${ }^{7}$ On a project level, resources, project management, etc., will play a role. No explicit attention will be given to these factors in this chapter.

Thornett ${ }^{8}$ describes benefits as improved quality of care, disease prevention and disease management of chronic physical illnesses. Why then, do these systems not diffuse into the health organizations? The adoption of IT in healthcare has increased, which underlines the importance of user requirements. ${ }^{9}$ In later work Beuscart-Zéphir links the adoption to the activities of the healthcare professionals. ${ }^{10}$ Fleisner and Hofkircher refer to the same problem when they conclude that relevant information will not be improved unless additional requirements are met. ${ }^{11}$

A multiple case study among 56 general practitioners (GPs) on the influence of resistance, relevance, requirements and resources on the introduction of an electronic prescription system (EPS) demonstrates that the EPS is not used in at least $72 \%$ of cases. First, a broad background of the model is given. To explain the non-use of the system we combine the notions of information usage of Delone and McLean ${ }^{12}$ and Davis, ${ }^{13}$ and the notion of innovation from Rogers. ${ }^{14}$ We use the semantic ladder from Stamper ${ }^{15}$ and information levels from Shannon and Weaver ${ }^{16}$ to straighten them out (social, pragmatic, semantic and syntactic levels). To explain relevance we will build on the notions of Saracevic. ${ }^{17}$ This will be described in the definition and framework section. Together these concepts build up a framework for an interview model that we used in all cases 
as described in the case study method (see p. 139). Finally we make conclusions for every determinant of the model.

\section{Background}

We can use a wide range of sources that discuss user perspectives in the introduction of IT. This section gives a short overview of intriguing literature. The aim is to demonstrate that 'requirements' is not the only user-related determinant of user adoption. Rather, it is an important determinant among other factors. One of the ultimate goals of our research project in this field is to propose a model that neatly balances the role of such factors.

First, we present the dimensions of the USE IT model to predict and evaluate innovation and diffusion of information systems: the innovation-dimension and the domain-dimension, which make four determinants for success: relevance, requirements, resistance and resources (Table 7.1).

Table 7.1 The USE IT model ${ }^{18}$

\begin{tabular}{lll}
\hline USE IT model & User domain & Information technology domain \\
\hline Product & Relevance & Requirements \\
Process & Resistance & Resources \\
\hline
\end{tabular}

By process, we mean the innovation process, similar to the process defined by Saarinen and Sääksjärvi ${ }^{19}$ and the innovation process structure of Larsen. ${ }^{20}$ The product is the result of this innovation process. This corresponds with the definition of the product by Saarinen and Sääksjärvi and the artefact structure in the framework of Larsen. Also the IT domain is part of the artefact structure; the user domain represents the organizational structure in Larsen's framework. The time horizon structure can be part of the requirements and the knowledge structure can be considered as an element of the resources.

Resistance is the personal attitude of all stakeholder groups towards the introduction of an information system (IS). ${ }^{21}$ The main IS-quality aspect of resistance is the attitude and the willingness to change. Pare and Elam ${ }^{3}$ also focus on the attitude of the professional when they assess clinical information systems. The end users have an important role because their norms and values determine the effectiveness of the information system.

Expectance of reduced quality of work life satisfaction, high complexity and the lack of trialability can result in resistance. ${ }^{14,22}$ Observability reduces resistance. ${ }^{14}$ Leavitt ${ }^{23}$ introduced four domains in which these risks will occur: tasks, structure, technology and people. Offenbeek and Koopman connect people with resistance potential because they can feel that the quality of their working life will be decreased. ${ }^{24}$ Mumford observed that user participation contributes to effective organizational change. ${ }^{25}$ When we focus on IT introduction more specifically, we again see a number of interesting literature sources. Thong and Yap discuss the user satisfaction approach to IT effectiveness. ${ }^{26}$ They mention the debatable 
operationalization, poor theoretical construct and misapplication as a result of the approach. On the basis of their review, they conclude that attitude is the construct that lies at the root of user-satisfaction, and suggest ways to improve operationalization and measurement of attitude. Paré and Elam studied attitudes, expectations and skills in relation to physicians' acceptance of IT systems. ${ }^{3}$ Physicians with formal training on computers were more knowledgeable about informatics concepts and reported that computers would be more beneficial to healthcare, although it is not clear whether the training causes this attitude. Venkatesh et al., ${ }^{27}$ however, make the hypothesis that 'attitude toward using technology will not have a significant influence on behavioral intention'. ${ }^{27}$

We argue this hypothesis in this chapter with previous results that resistance was found to be the cumulative effect of the other three determinants. ${ }^{28}$ But attitude, permission and capability of the end user will influence the adoption apart from the other dimensions.

The relevance determinant is defined by Schuring and Spil as: 'the degree to which the user expects that the IT-system will solve his problems or will help to realize his actually relevant goals'. ${ }^{29}$ The word 'expects' expresses that relevance is a factor that is important in the course of the adoption process, not only in evaluation. The word 'actually' is crucial in their view of relevance. Relevance is not to be confused with the degree to which the user considers outcomes as being positive. The set of outcome dimensions that someone considers 'positive' is larger than the set of outcome dimensions that are relevant.

Imagine a physician, who basically considers IT outcomes of a computer decision support system, such as assistance in diagnosis, disease prevention or more appropriate dosing of drugs, as 'positive'. This does not automatically imply that the IT adoption is relevant to him; it is only relevant if these dimensions are high on his 'goal agenda'. Relevance defined in this way comprises relative advantage, $^{14}$ net benefits, ${ }^{30}$ perceived usefulness ${ }^{13}$ and job relevance, ${ }^{31}$ and results in task support satisfaction, which is a criterion for user satisfaction. ${ }^{22}$ Also, it becomes clear that user priorities regarding IT innovations vary strongly.

The functional uncertainty is often described in information systems literature. It occurs in the task domain of Leavitt. In each situation, the interpretation and the meaning can be different. Therefore, it is necessary to establish a functional specification with users and providers of the information systems. Henry and Stone $^{32}$ state this to be information quality. Larsen ${ }^{20}$ notes, however, 'the quality of the IS/IT product is a necessary but not sufficient prerequisite for IS innovation success. The people within the organizations determine the outcome.'

Within the healthcare sector, Walley and Davies conducted a study of the internal barriers to technological IT advancement in the healthcare sector. ${ }^{5}$ The involvement of stakeholders is arguably one of the most distinctive characteristics of IT projects. In their study on the implementation of an electronic prescription system, Schuring and Spil found that lack of relevance was the major determinant that explained the failure of the implementation. ${ }^{28}$

The requirements determinant evaluates the meaning of the information system. Requirements are defined as the degree to which the user needs are satisfied with the product quality of the innovation. ${ }^{33}$ This includes such aspects as the functional capability, the ease of start-up and the ease of use.

Meeting the end-user's requirements results in high information quality, system quality, ${ }^{30}$ high interface satisfaction ${ }^{22}$ and high compatibility. ${ }^{14}$ There 
are instruments to identify user needs, but Walley and Davies question whether they are actually used. ${ }^{5}$ Van der Pijl shows that there is more to say about people than just resistance or user participation. ${ }^{34}$ Both users and providers of information systems have their own targets, not necessarily going hand in hand. A central question is whether the provider intention is the same as the user interpretation. ${ }^{35}$ We think that a requirements contract between user and provider can help to bridge the information gap. ${ }^{36}$

Resources are defined as the degree to which material and immaterial goods are available to design, operate and maintain the information system. ${ }^{33}$ The main focus of the determinant resources will be on the people and on the costs these people cause. Next to that the reliability of the IT and the information systems are considered. Resources defined in this way refer to service and system quality, ${ }^{30}$ management support and mature IS function. ${ }^{19}$ Resources (human, physical and monetary components ${ }^{37}$ ) are needed to implement the new information system into the organization. The human resources can be insufficient in both time and experience (risk of technology). Insufficient material resources will have a limiting influence on the other three risk domains. ${ }^{24}$

To measure the determinants the USE IT tool consists of structured interviews. In this way a more precise insight can be obtained into the nature and relevance of problems and solutions, before implementation and this insight can be tested with the same tool during the evaluation of the implementation. In the next section we will elaborate each determinant of the USE IT model.

\section{USE IT: definition and framework}

\section{Resistance}

The tendency of human beings to resist and fear new and unknown things and the willingness to stick to the familiar procedures has been studied widely. ${ }^{38,39}$ Attributing the rejection of innovations only to anxiety and fear of change, however, is an oversimplified view of the process of technology transfer. ${ }^{40}$ Carey $^{41}$ finds a correlation between acceptance of change and variables such as previous use (experience), education and current usage of a new system. ${ }^{41}$ She also reports commitment, exposure to change and preparation for change as being important for successful implementation of new technologies and systems. So a much broader view on the subject of resistance is appropriate. We position it on the social level of the semantic ladder. ${ }^{15}$

We start with the first known published reference to research on resistance to change in organizations by Coch and French. ${ }^{42}$ They were early explorers in the world of resistance when they concluded by preventing or greatly modifying group resistance to change, this concomitant to change may well be greatly reduced'. Besides taking the notion of resistance influencing successful change, they state that it can be different on group and individual level. Later change management literature categorizes into the individual, group and organizational (structure) levels.

On the group level, Lewin refers to 'group standards' when looking for reasons for resistance to change. ${ }^{43} \mathrm{He}$ concludes that the more individuals take group standards of their environment, the greater will the resistance to change of an 
individual group member be. Lewin further continues that group standards with social values are often referred to as 'social habits'. The way to reduce the level of resistance may thus be either to diminish the strength of the value of the group standard or to change social habits themselves.

Both Lawrence ${ }^{44}$ and Zuboff ${ }^{45}$ conclude that resistance is not simply an irrational phenomenon to be overcome. ${ }^{46}$ Zuboff sees positive and negative aspects to resistance. More authors describe this healing effect of resistance. ${ }^{47-49}$ Insightful and well-intended debate, criticism or disagreement do not necessarily equate to negative resistance, but rather may be intended to produce better understanding as well as additional options and solutions. Rogers ${ }^{14}$ also explains that it is perfectly rational for later adopters to be more hesitating about the introduction of an innovation; they do not have sufficient resources to overcome the consequences of adoption failure.

Kotter and Schlesinger ${ }^{50}$ diagnose resistance from the negative viewpoint as:

- parochial self-interest (fear of loosing something worthwhile ${ }^{51}$ )

- misunderstanding and lack of trust

- different assessments (belief that change is worthless ${ }^{51}$ )

- low tolerance for change.

Fuller also discovers different levels of concern regarding resistance. ${ }^{52}$ Selfconcern can be seen in awareness, personal commitment and personal consequences. Task concern is related to controlling the change, and cooperation concern sees both concerns in collaboration and reengineering. Schmidt et al., ${ }^{53}$ whose study was a mirror of control for this study, refers to Zmud, ${ }^{54}$ who adds a fourth environmental category. Lapointe et al. applies these categories in explaining the dynamics of IT adoption in healthcare. ${ }^{55}$ She based her theory on the theory of reasoned action where individual behaviour is directly determined by one variable intention which, in turn, is determined by two variables: attitude and subjective norms'. In line with Scott, ${ }^{56}$ Prasad and Prasad $^{57}$ make the distinction between formal and informal (routine) resistance. Strebel ${ }^{58}$ already described this as personal compact, formally a job description and appraisal, but informally psychological (mutual expectations) and socially (cultural values). This brings us back to the notion that change is intensely personal ${ }^{59}$ and therefore our empirical material is gathered very close to professionals coping with the change.

Kotter and Schlesinger are mainly interested in the self-concern. Mittelstaedt et al. adds the inability of either individual or group to cope with the change. ${ }^{60}$ Also the situation can call for postponement. The situational factors we see as mainly emerging on organizational level are:

- not for them (reject)

- unwilling or unable (accept)

- postpone (time and situation) (accept).

Gatignon and Robertson ${ }^{61}$ and Szmigin and Foxall ${ }^{62}$ use sort-like distinctions: the latter introduce opposition instead of unwilling or unable. Ram and Sheth ${ }^{63}$ call this habit resistance and also relate to Rogers, ${ }^{14}$ when they state that often an initial resistance has to be overcome. Please note that most of the literature in this 
paragraph is based on resistance of consumers. It might not always apply in a healthcare environment.

Offenbeek and Koopman introduce the resistance potential and make a distinction between change-ability of the problem system and desired change. ${ }^{24}$ This potential of resistance would be people-determined resistance according to Markus. ${ }^{64}$ System-determined resistance is handled in the technical determinant of IS success but the interaction-determined resistance, which is mainly political (inter) organizational resistance, can only be seen within the reasons to postpone of Mittelstaedt et al. ${ }^{60}$

Other publications on the subject of resistance challenge or enhance the 'accepted' concepts. ${ }^{65}$ Piderit suggests that resistance to change is a complex, multidimensional response with emotional, cognitive, and intentional components. ${ }^{48}$ For example, no participation or not enough communication may result in an emotionally resistant attitude to the changes, even though the changes make good business sense (cognitive). Alternatively, initially enthusiastic (emotional) and clearly seeing the need for change (cognitive), people give up (i.e. our intentions change) because they are not given the support they expect and think they'll need in order to make the changes happen. It is rare that employees are all negative or all positive across the three dimensions. It is important to remember that resistance to change is normal and frequently functional.

'Moving too quickly toward congruent positive attitudes toward a proposed change might cut off the discussion and improvisation that may be necessary for revising the initial change proposal in an adaptive manner.' In other words, discussion, disagreement and experimentation can lead consistently to more successful change, whereas effective communication and participation are powerful tools for overcoming and avoiding misunderstandings. ${ }^{49}$

Zaltman and Duncan's ${ }^{66}$ resistance framework discusses four categories of barriers, 'cultural, social, organizational, and psychological', that can obstruct change. ${ }^{66}$ These categories are in turn broken down into a total of 18 resistance factors, which disrupt change efforts and distort adopter perceptions of innovations. This framework can be useful because it explores change from the opposite perspective to most other models. By focusing attention on factors that erect barriers to change, Zaltman and Duncan help to recognize such obstacles as they arise or even to identify and address their underlying issues before they arise. It is important to note that a given individual can harbor intense pro-change and pro-resistance sentiments simultaneously.

Though detailed in its 18 factors, this framework is not suitable for the goal of this study. More appropriate is a model with its roots in change management, educational and training literature, structuring resistance and affection into three categories: ability, attitude and opportunity. Metselaar et al. ${ }^{67}$ describe this used in training against (negative) and with (positive) resistance based on a concept from the social psychology. ${ }^{68}$ Lanning $^{39}$ comes with the same result in an empirical study for a planned change approach. We adopt these findings into our 'USE framework for resistance to IT change', where we should reckon that the main focus of these shifts from (inter)organizational, to group, to individual. In line with the USE IT model, ${ }^{21}$ this subdivision is made into macro- and microresistance (see Figure 7.1 , p. 136). 


\section{Attitude (will) to change (micro-resistance)}

People who are expected to participate in the change project must have personal motivation and a sincere will to engage themselves in the development. Comprehension and acceptance of the basic idea in the project is an important condition. Will does not occur unless real effort at developing the organization can be perceived.

\section{Ability to change (macro-resistance)}

The level of knowledge and skills of those who are involved in a 'change' project needs to be high enough to be able to contribute to the project. Job-specific skills enabling people to use new tools and technology and to act according to new procedures and tasks must be adequate. But ability also means comprehension of project vision and understanding one's own role in implementing the new technology. The user experience also adds up to the ability to change.

\section{Opportunity to change (macro-resistance)}

There is a need for organizational systems (surrounding people and structures) to support the development process and implementation of the new technology. Sufficient resources, top management support and commitment are essential to give everybody the feeling that change and development can be achieved.

These subdimensions of resistance fit underneath the user satisfaction research model of Mahmood et al. ${ }^{69}$ as they call it user background and organizational support. The perceived benefits that complete the user satisfaction are in the USE IT model situated under the relevance determinant ${ }^{70}$ and described in the next section.

\section{Relevance}

Saracevic defines relevance as a measure of the effectiveness of a contact between a source and a destination in a communication process. ${ }^{17}$ This is a somewhat abstract wording of what we would call the degree to which the user expects that the IT system will solve their problems or help to realize their actually relevant goals. There are three dimensions that are kept implicit in Saracevic's definition that we wish to stress. We use the word 'expects', since we want to make more explicit that relevance is a factor that is important in the course of the adoption process, not only in evaluation. Second, instead of effectiveness we use 'solve problems and goals'. By doing so, we imply that effectiveness has two dimensions: to take away existing negative consequences (problems) and to reward with positive consequences (reach goals). Third, the word 'actual' is crucial in our view of relevance. Relevance is not to be confused with the degree to which the user considers outcomes as being positive. The set of outcome dimensions that someone considers 'positive' is larger than the set of outcome dimensions that are relevant. Imagine a physician who basically considers IT outcomes of a computer decision support system, such as, assistance in diagnosis, disease prevention or more appropriate dosing of drugs, ${ }^{8}$ as 'positive'. This does not automatically imply that the IT adoption is relevant to him. It is only relevant if these outcomes are high on his goal agenda. That is why we use the word 'actual'. 
Again, this is a more explicit wording of a dimension that is implicitly included where Saracevic uses the word 'effectiveness' in his definition. The actually relevant goals may be a mix of short-term goals and long-term goals. If, for example, smooth communication with hospitals or pharmacy is his prime actual problem or goal, he will only consider the IT innovation as relevant when it actually helps to improve that communication, notwithstanding the fact that he might have a positive attitude towards that innovation as long as the innovation helps to solve other problems or other goals that are on the lower positions in his agenda ranking. We discovered in our case studies that it is not sufficient for an innovation to effectuate a positive attitude among users. The IT innovation should be relevant. ${ }^{29}$

Micro-relevance is a related concept that can be used to describe a similar phenomenon once the new IT is installed. Micro-relevance is defined as the degree to which IT use helps to solve the here-and-now problem of the user in his working process'. The use of new equipment or new IT procedures is a conscious activity. In every conscious activity that is goal-oriented to a specific goal, there is a reason why that course of action is being chosen. Similar to what was discussed above on 'relevance', not every course of action that a user basically considers as 'positive' is 'micro-relevant'. Again, let's illustrate this with an example. Imagine that a patient with a viral infection visits a physician. The physician might notice the similarity to a number of other patients he has met that week and decide on diagnosis and treatment fairly quickly. To this doctor, the use of a decision support system to determine diagnosis is not micro-relevant. However, a colleague of his may not feel so confident and thus use the system. We discovered that micro-relevance is a key factor in explaining IT use in our case studies. Figure 7.1 ( see p. 136) gives an overview of relevance as we propose to use it.

Relevance and micro-relevance are notable refinements of the way the role of the user is being discussed in the existing literature. Thornett ${ }^{8}$ implicitly refers to relevance and micro-relevance when he discusses limited adoption and use of decision support systems (DSS) by primary physicians where 'consultation time is lengthened by their use and there is no appreciable impact on patient satisfaction' $^{8}$ It is an example where other outcomes that are basically considered as positive (as mentioned above: better diagnosis, more appropriate dosing of drugs, and other) are overruled by limited relevance and micro-relevance.

Saracevic provides a historic positioning of relevance. ${ }^{17}$ The roots lay in the 1930 s and 1940s when the distinction between information and relevant information was made by Bradford. ${ }^{17}$ In order to make the distinction between relevant and non-relevant information, he discusses the nature of communication. By doing so, he recognizes that relevance to a subject depends on specific dimensions, such as for example, the subject's knowledge, representation and values. He discusses a number of (philosophical) approaches to relevance. The elaboration we propose above builds on the radical pragmatism perspective or, more specifically, Cooper's utility function: 'Relevance is simply a cover term of whatever the user finds to be of value about the system output, whatever its usefulness, its entertainment, or aesthetic value, or anything else' ${ }^{71}$ Wilson adds to this that relevance is situational. ${ }^{72}$ Ballantine et al. put it in the following way: 'Depending on the type of task, the information generated by the system may be more or less appropriate, which will affect its success or failure'. ${ }^{73}$ Saracevic distinguishes various other approaches to relevance, of which a number focus on 
the basic source of relevance, like, logical relevance, the nature of interference and the pertinent view of relevance. ${ }^{17}$ We are very much aware of the fact that our elaboration of relevance does not in full retain the differences between those points of view. It is merely a practical elaboration that we use to predict user adoption.

The pragmatic perspective ${ }^{74}$ of relevance that we choose resembles the notion of 'relative advantage' as discussed in the innovation diffusion literature by Rogers. Rogers ${ }^{14,75}$ reserves a central role for 'relative advantage', which is the user's view of 'the degree to which an innovation is better than the idea it supersedes'. Relative advantage can be economic or social. Rogers states: 'The nature of the innovation largely determines what specific type of relative advantage is important to adopters, although the characteristics of the potential adopter also affect which dimensions of relative advantage are most important'. Based on a review of hundreds of empirical studies, Rogers concludes that relative advantage explains $49 \%$ of the rate of adoption of innovations.

It is most notable that the organizational factors are not explicitly included in our user relevance framework. It should be kept in mind that the user's agenda of problems and goals depend on his role in society. ${ }^{76}$ The influence of the organization on this agenda depends on many aspects, including the involvement with other organizations, time and place. As a consequence, our framework reflects the actual impact that organizational goals and preferences have on the user, and thus, on organizational behavior. 


\section{Macro-resistance \\ Definition: the degree to which the surroundings and locality negatively influences the users of IT

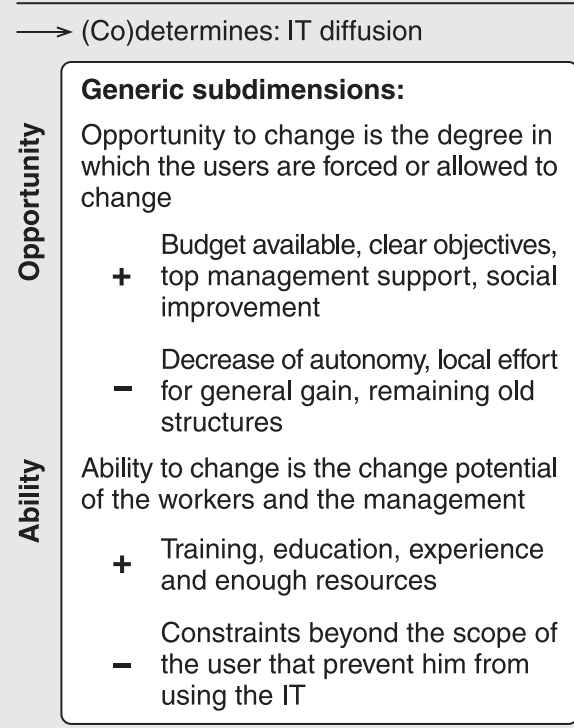

\section{Micro-resistance $=$ attitude}

Definition: the degree to which IT users themselves are opposing or postponing the IT change

1 Parochial self-interest

2 Misunderstanding or lack of trust

3 Different assessments

4 Low tolerance of change

\section{Macro-relevance}

Definition: the degree to which the user expects that the IT system will solve his problems or help to realize his actually relevant goals

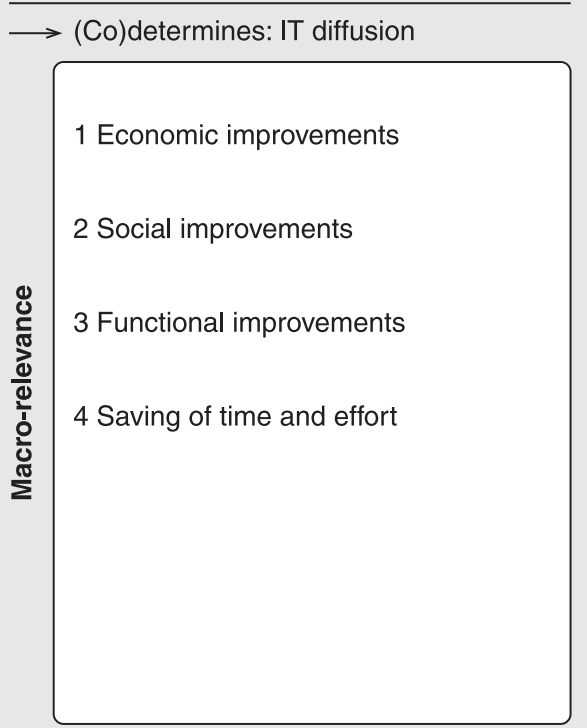

\section{Micro-relevance}

Definition: the degree to which IT use helps to solve the here-and-now problem of the user in his working process

1 Absolute value of relevance

2 Here-and-now value

3 Low initial costs

4 Immediacy of the reward

Figure 7.1 USE framework for resistance and relevance of IT change.

\section{Requirements}

At the semantic level ${ }^{12,15,16}$ we are concerned with how pattern types relate to what happens in the world. On this level we deal with the meaning of the system, but this term brings a lot of different meanings about its definition. ${ }^{77}$ The meaning of a sign relates to the response the sign elicits in a given social setting. ${ }^{78}$ It is situational of nature since we have a range of pattern types that signify a certain meaning and a user (group) that interprets the expression. ${ }^{79}$ Therefore it is necessary to establish requirements as thoroughly as possible. Wieringa defines requirements as desired properties needed to achieve the desired composite system properties. ${ }^{80}$ Pressman makes a distinction between normal requirements, 
expected requirements and exiting requirements. ${ }^{81}$ Before defining requirements ourselves we want to study the problem at a deeper level.

'Many system designers do not appear to realize that with their present approach they are designing only partial systems' ${ }^{25}$ Pressman argues that all needs of the end users should be identified. The notion of variance emerged from some early sociotechnical work design experiments in Norway. ${ }^{82}$ A variance is defined as 'a tendency for a system or subsystem to deviate from some desired or expected norm or standard'. Key variances are the deviations on goals and functions; operational variances stem from the organizational problems. Together they get close to the main problem that we are addressing, the information gap between designer and user.

Iivari and Koskela ${ }^{74}$ include three quality constructs on the semantic level, which they call the input/output requirements: informativeness, accessibility and adaptability. Informativeness describes the potentiality of the information systems, accessibility the quality of the user-IS interaction and adaptability points to the ability of the systems to change.

DeLone and McLean enumerate the criteria for IS success from nine earlier studies. ${ }^{12}$ They declare themselves that there is not 'one' measure of IS success but there are many dependent variables. They call their taxonomy Semantic Level Information Quality. Usefulness or relevance is mentioned eight times in the nine studies. Schuring and Spil have studied the importance of relevance and made it a separate determinant on the pragmatic level. ${ }^{29}$ Timeliness is empirically used five times and adopted in our model. We keep using the term 'accessibility' as a broader term, including convenience of access. Accuracy is studied four times and adopted under informativeness. We do not understand why there is no notion of adaptibility or ability to integrate in the DeLone and McLean study. We adopt ability to integrate as the degree that the new system is imbedded in the organization.

Brender and McNair use the ISO 900x structure and use the strategic, tactical and operational level to perform their user requirements specification. ${ }^{83}$ Larsen also makes this distinction. ${ }^{20}$ The strategic level is concerned with the problem definition, including objectives and global task description. The tactical level is interpreted as a preferred approach and the operational level includes a set of functional, performance and capacity criteria.

The requirements determinant is defined as 'the degree to which the user needs are satisfied with the product quality of the innovation'. We divide the requirements into macro- and micro-requirements (see Figure 7.2, overleaf).

- Strategic general requirements and tactical approach is the degree to which the users agree with the objectives and methods used.

- Functional requirements and performance requirements specify what the content of the innovation should be. In this study we chose timeliness (accessibility), accurateness (informativeness), ability to integrate and content as main quality criteria but we acknowledge that this is specific for this study and not a complete list.

\section{Resources}

Under the semantic level most researchers situate the syntactical level. ${ }^{74}$ They give efficiency criteria to measure the quality of the information system on this 
level (design costs, operations costs and maintenance costs). Shannon and Weaver call it level A, the technical problem, ${ }^{16}$ and Stamper divides it into three levels (syntactic, empirical and physical). ${ }^{15}$ Main quality criteria on these levels are formal specification, reliability and costs.

The resources determinant is defined as the degree to which material and immaterial goods are available to design, operate and maintain the information system'.

The design costs can mainly be seen as time and capability of users and designers, ${ }^{84}$ but also the size of the project and the complexity of the problem could be measured to assess the risk of the innovation design. Also hardware and software costs fall under this header. Formal specification on the syntactic level can be checked on the semantic level with the quality criterion accurateness (data, system and information).

The operations costs are mainly human resources but the abnormal costs can be derived from the reliability of the system. ${ }^{74}$

The maintenance costs can be shown with the quality criteria adaptability and portability that also link to the ability to integrate on a higher level.

\section{Requirements \\ Definition: the degree to which the user needs are satisfied with the product quality of the innovation

\begin{tabular}{|l}
\hline (Co)determines: IT diffusion \\
\hline $\begin{array}{l}\text { Generic subdimensions: } \\
\text { Strategic general requirements and } \\
\text { tactical approach is the degree in which } \\
\text { the users agree with the objectives and } \\
\text { methods used }\end{array}$ \\
$+\begin{array}{l}\text { Clear objectives, iterative } \\
\text { approach, users involved }\end{array}$ \\
$-\quad \begin{array}{l}\text { Unclear communication, no } \\
\text { participation, education }\end{array}$ \\
Functional requirements and \\
performance requirements specify what \\
the content of the innovation should be \\
$+\quad \begin{array}{l}\text { Timeliness, accurateness, ability } \\
\text { to integrate, content }\end{array}$ \\
$-\quad$ Fuzziness, non-contract
\end{tabular}

\section{Resources}

Definition: the degree to which material and immaterial goods are available to design, operate and maintain the system

\begin{tabular}{|c|c|}
\hline \multicolumn{2}{|c|}{$\longrightarrow$ (Co)determines: IT use } \\
\hline \multirow{4}{*}{$\begin{array}{l}\bar{\pi} \\
\frac{\pi}{2} \\
\frac{\pi}{\pi} \\
\Sigma\end{array}$} & Generic subdimensions: \\
\hline & 1 Costs \\
\hline & 2 Hardware and software \\
\hline & 3 User and designer time \\
\hline \multirow{3}{*}{ 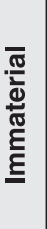 } & 4 Adaptability \\
\hline & 5 Capabilities \\
\hline & 6 Reliability \\
\hline
\end{tabular}

Figure 7.2 IT framework for requirements and resources determinants. 


\section{Multiple case studies results}

\section{Case study method}

Nykänen distinguishes four major evaluation perspectives: goal-oriented, standardized, effectiveness-based and stakeholder-based perspective. ${ }^{85}$ In the goaloriented evaluation the emphasis is on rationality: measurement criteria and the means to achieve the goal can be derived from the goal itself. This is possible if the criteria are clear and there are no conflicts of interest among the stakeholders. The downside of the goal-oriented perspective is the inability to see other than the anticipated consequences of actions. In the standardized (or normative) evaluation, causes and consequences are not in the scope of interest, but compliance with rules, agreements, budgets and principles is monitored (e.g. quality systems). In the effectiveness-based view the input/output ratio of actions is economically evaluated. The problem with this perspective is in expressing intangibles (e.g. health) in monetary terms. According to the stakeholder-based perspective, all actions are not always rational, aiming at one mutual goal, and therefore the criteria should be collected from several stakeholders' views. The perspective has a lot of qualitative characteristics and it can be a quite laborious framework for a study design. ${ }^{86}$

This study used the stakeholder-based perspective and was set up to both assess the situation regarding the electronic prescription system 'EVS' (elektronisch voorschriftsysteem) in the Netherlands and the theory that is described above that was set up to provide an instrument that could be used to analyze the diffusion situation of the prescription system. This resulted in a case study protocol that covers all the topics that are mentioned in the framework in open-ended questions. In line with the case study approach by Yin, ${ }^{87}$ we discerned different case situations on the basis of our theoretical framework. Particularly, the network situation (individual, group practice, healthcare center) of GPs and the degree of adoption of previous ideas (laggard (no computer) to innovator (using ICPC codes and electronic patient record) ) served as a basis to make categories of GPs. A total of 56 case studies were conducted. Each GP was visited in their own working situation and interviewed for over an hour. We agree with Brender that the kernel point of assessment is that of understanding the business processes. ${ }^{88}$

\section{Electronic prescription in The Netherlands: an introduction}

The Electronic Prescription System (EPS) that we studied is an IT system that gives GPs recommendations on the therapy that can be given to patients on the basis of the diagnosis of the practitioner. ${ }^{89}$ This diagnosis is coded by use of the International Code for Primary Care (ICPC). The value of the system, as compared to the traditional situation, lies in the fact that the system takes patient characteristics into account. The recommended therapy is customized on the basis of the age and gender of the patient, and existing pharmaceutical therapy for other diseases, and is based on the formulary, which is a list of drug preferences that is set up by professional associations. Figure 7.3 shows the working principle of the EVS. 


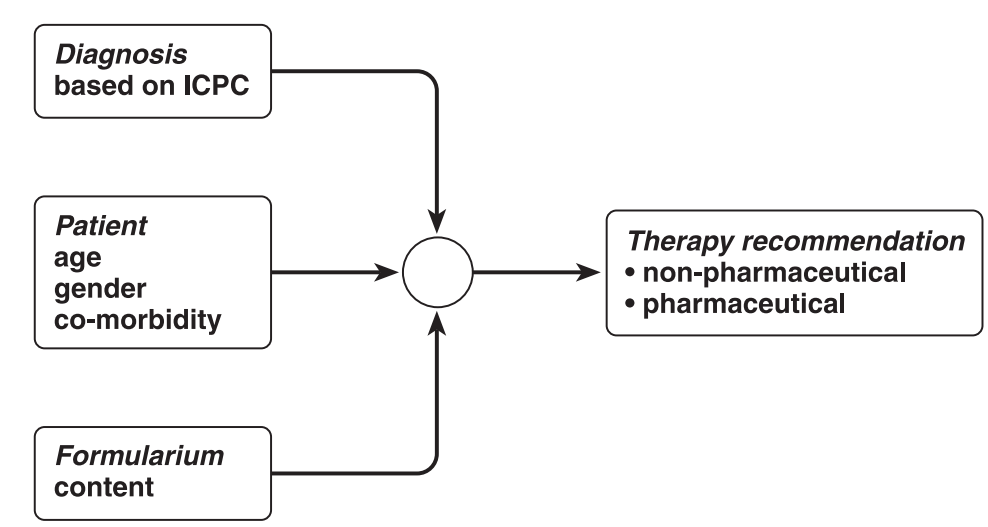

Figure 7.3 Working principle of the EVS electronic prescription system.

The EVS is available as an add-on to practically all information systems that exist for GPs in this country (GP-IS).

\section{Empirical results of GP electronic prescription system}

\section{Empirical resistance of GP}

The main problem formulation for this study was to find the obstacles of implementation of the EPS system. Under the header 'resistance of the GP', questions were asked about problems or wishes that the GP experienced as important at the moment of asking, during implementation of the EPS. Figure 7.1 gives an overview of all the situational resistance factors mentioned. Here we will summarize the results of the main five:

- time $(55 \%)$

- user interface $33 \%$

- free choice $30 \%$

- ICPC $27 \%$

- unwilling $20 \%$.

Fifty-five percent of the GPs said they were under immense time pressure. We think that this made the EPS less relevant to the GPs, ${ }^{70}$ but it also levered the resistance because the GPs thought they would need more time for a consult using the EPS instead of less time. These statements are confirmed by British research. ${ }^{90}$

Thirty-three percent of the GPs had problems with the quality of the software. The main problems were not related to the new EPS but more to the old GP IS that was not able to give a good user interface. The EPS we described as 'spoilers on a T-Ford'. ${ }^{91}$

Thirty percent of the GPs say they do not want to be written the law by a new system and want to remain free to choose in prescribing drugs to their patients. Some say the recommendations are too conservative, others say they want to be able to try out new ideas. All of them say they want the freedom of choice. 
Twenty seven percent of the GPs think that the ICPC is a problem when using the EPS system. Some state that it is rather difficult to find a related ICPC to the diagnosed disease. Others state that it is not necessary to use ICPC for general diseases like flu because it costs time and it does not help the process.

Twenty percent of the GPs are unwilling to use the EPS. That means that they have not looked at it and will not look at it just because they do not like the change. Here we see clearly a low tolerance of change.

\section{Empirical relevance to the GP}

Under the header 'relevance for the GP', questions were asked about problems or wishes that the GP experienced as important at the moment of asking, during implementation of the EPS. Figure 7.4 gives an overview of all the situational relevance factors mentioned. Here we will summarize the results of the main seven:
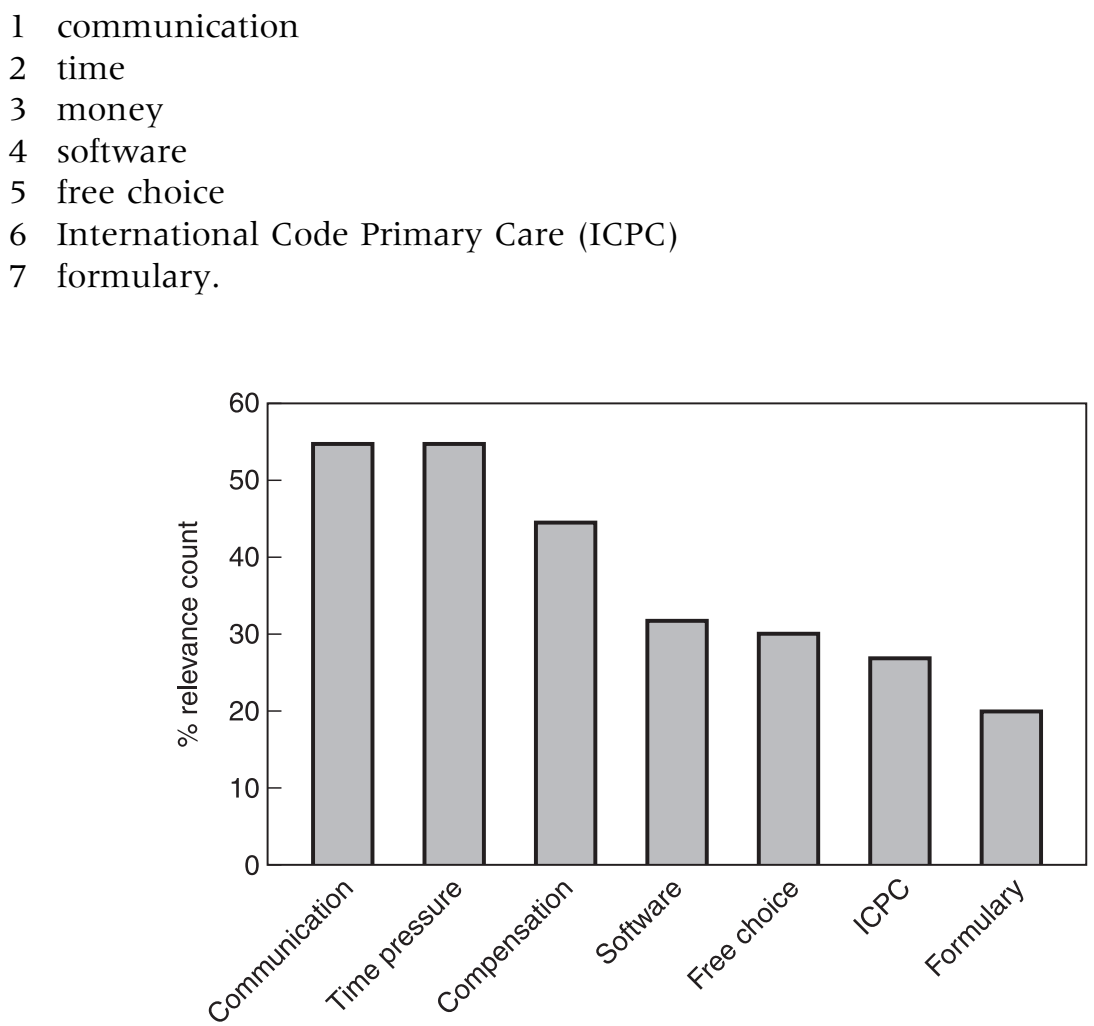

Figure 7.4 Multiple case study results on relevance.

In more than half of the case studies, the GPs said that improvements have to be made to communication with colleagues, pharmacists and hospitals. They state that a standard way of working is very important to reach such a communication. The EPS system does not deliver these features. Saarinen and Saaksjarvi measured the 
improved internal communication and improved inter-organizational communication under the header 'impact of the IS on the organization' ${ }^{19}$ None of these success factors was satisfied in our cases.

In $55 \%$ of the case studies, and independently of each other (the term was not mentioned by the interviewee), the GPs stated that there should be a diminishing of the time pressure. Both in the description of the EPS, as found in the international literature, EPS will not diminish the time of the consult. ${ }^{8,90}$

Forty-five percent of the case studies reported that the GP expected a fee in return for going to the trouble of implementing and using EPS. At the moment of interviewing it was not clear what financial profit the new system would deliver for the GP. What was known was that it would save the government and insurance companies a large amount of money on costs of medicine.

In about 20 case studies, lack of trust in the existing software and in the software supplier were mentioned as a barrier for (wanting to) use the new EPS. They said that first things had to change in the GP-IS market and in the GP-IS itself before EPS could be a success.

About the same number of GPs want to retain freedom of choice in prescribing medication for their patients. Although this seems to be a resistance matter it is also a relevance matter, because the EPS does not comprehend new ideas and new treatments that are already known in the general practice.

Although the use of ICPC seems useful to many GPs (in structuring and communicating), the time it will need to find the right code and the omissions of some codes form a barrier for EPS use.

Twenty percent of the GPs make use of a personal or regional formulary. The EPS makes use of a formulary from the Dutch Council for GPs and GPs are often unable to keep their own formulary when an update of the software is installed.

Finally, once the computer system was installed, use of the system was mostly sparse. The way of working was relatively complicated and added relatively little value in most patient-doctor contacts.

\section{Empirical requirements to the GP}

\section{General requirements}

The objectives for this innovation were mainly money driven. The system should decrease prescription costs by $€ 150$ million per annum. To the GPs we interviewed, the goals were not clear.

Functional and performance requirements

\section{Content}

The functionality of the GP information system can be divided into administrative functionality and medical functionality. We observed that the administrative use of the system has the upperhand. Only 15 GPs $(27.3 \%)$ made use of the SOAP (subjective, objective, assessment, plan) module in the systems, which is a prerequisite for the use of the EPS. 
Communication with other GPs, hospitals and pharmacists is a requirement that is high on the agenda of the GP (55\%). However, the new EPS does not support this communication at all.

\section{Timeliness}

Time pressure is one of the most important problems facing today's GPs. Timeliness of the system is therefore an important performance criterion. Due to a bad user interface, the GPs are not able to work several records in parallel and therefore lose time in opening and closing the patient's record.

\section{Accurateness}

The accurateness of the system is good and might be too good. The system was rigidly designed to avoid failures and therefore has many signal functions. For instance, when prescribing medicines for influenza, the GP is given a lot of alternatives and warnings where he or she already knows exactly what to prescribe.

Also the accurateness of input is a problem because $30 \%$ of the GPs think it is unnecessary and sometimes difficult to generate a code for all 'vague' diseases like stomach ache, headache and so forth.

\section{Ability to integrate}

The EPS is delivered on CD-ROM as a stand-alone system. This means that it is not integrated in the GP information system and also not in the communication configuration of the GP. The GP therefore has to start the program for each patient and cannot work in parallel, the more so because the system is not window-based.

\section{Empirical resources to the GP}

Costs

For the GPs there are no costs involved in getting the system but they need time to install and operate the system. In general $€ 30$ million was spent in designing and implementing the system. Strangely, all system suppliers said they did not get money to change their GP information system. The operating and maintenance costs are not seen as a problem by the GP. The reward for using the system is seen as a problem. Extra office support was promised by the government, but in practice was not given and was not clear.

\section{Hardware and software}

The GPs have no faith in the suppliers of GP information systems. Mergers and take-overs mean the suppliers and GPs are in a deadlock situation where maintenance seems to be the only thing that happens. Thirty percent of the GPs regard the quality of the GP information system as an obstacle to using the new EPS. We described it as 'spoilers on a T-Ford'.

\section{User and designer time}

From our questions to the GPs it is very difficult to analyze the time spent in designing the system. In operating the system the GPs lose time because they 
have to put more information in the computer and use some time in consulting the system. With an average time of six minutes per consult this is a big problem.

\section{Adaptability}

From a maintenance point of view, the system is very adaptable, since a new version simply has to be distributed without having to change the rest of the GP system. Nevertheless, we advised that the entire GP system had to be updated with the EPS as an integrative communicative subsystem.

\section{Capabilities}

One of our final conclusions in the main report ${ }^{91}$ is that we think it is crucial for the continuance of the project that the average GP is addressed rather than the innovative GP. In designing the system, GPs were involved, but only voluntary GPs who were bound to consist of the innovative GPs.

We also found big differences in IT capabilities. Some GPs still used the paper record and no computer and some GPs did all their activities on the computer. Due to these differing IT capabilities, various introduction programs will be necessary to diffuse the system into all GP practices.

\section{Reliability}

According to the GPs, the system is reliable. Breakdown of the system seldom occurs. The maintenance is reasonable, although one GP states: 'We have to be at a patient's house in ten minutes and they can stay away for ten days.'

\section{Conclusions}

Resistance of GPs is not the determinant of the use of the EPS (only 27\%). Resistance is the cumulative consequence of effects of the other determinants and therefore it looks as if resistance is the most important determinant. This means that many studies work on the effect and not on the cause of the lack of IT use.

Relevance has long since been a central notion to IT theory. The elaborated approach that we proposed in this chapter was used in 56 case studies. These cases provided us with enough evidence that for this particular (electronic prescription) system in this particular (healthcare) branch, relevance was the most important determinant for failure of diffusion and use of the system.

Although in many studies the social criteria of success are mentioned as more important than the technical criteria, we cannot confirm this for these 56 cases. In most cases, the resources were not sufficient to use the new EPS. On top of that the requirements of the users were not sufficiently met by the system. We would like to draw the following conclusion for the healthcare organizations. Before starting a new project to build or buy a new information system in healthcare organizations it is necessary to explicitly measure the resources available. The next step is to make a contract containing functional and performance requirements, both agreed upon by a broad group (laggards and innovators alike) of end users and the designers responsible for the system.

Finally, we can conclude that assessing the IT diffusion and IT use of the EPS with the USE IT model was a multiple case study balancing sociotechnical 
determinants. The model has been used in two other healthcare situations and is now been used in a telecare project for stroke patients and a diffusion project of an electronic patient record in a hospital. We would encourage other researchers to work with the model in other environments (including outside healthcare) and we would also encourage the use of the interview schedule.

\section{References}

1 Ammenwerth E et al. (2003) Evaluation of health information systems-problems and challenges. International Journal of Medical Informatics. 71(2-3): 125-35.

2 Berg M (2001) Implementing information systems in healthcare organizations: myths and challenges. International Journal of Medical Informatics. 64: 143-56.

3 Pare G and Elam J (1999) Physicians' acceptance of clinical information systems: an empirical look at attitudes expectations and skills. International Journal of Healthcare Technology and Management. 1(1): 46-61.

4 Southon G (1999) IT, change and evaluation: an overview of the role of evaluation in health services. International Journal of Medical Informatics. 56: 125-33.

5 Walley P and Davies C (2001) Implementing IT in NHS hospitals - internal barriers to technological advancement. In Proceedings of the First Hospital of the Future Conference. Enschede, The Netherlands.

6 Schuring RW and Spil TAM (2004) HCADO: IS implementation, adoption and diffusion in healthcare. In: Call for proposals for the 38th HICSS conference, Hawaii (www.HICSS.org).

7 Kimberley JR and Evanisko MJ (1981) Organizational innovation: the influence of individual, organizational, and contextual factors on hospital adoption of technological and administrative innovations. Academy of Management Journal. 24(4): 400-17.

8 Thornett AM (2001) Computer decision support systems in general practice. International Journal of Information Management. 21: 39-47.

9 Beuscart-Zéphir MC (1997) Cognitive evaluation: how to assess the usability of information technology in healthcare. Computer Methods and Programs in Biomedicine. 54: 19-28.

10 Beuscart-Zéphir MC et al. (2001) Integrating users' activity modeling in the design and assessment of hospital electronic patient records: the example of anesthesia. International Journal of Medical Informatics. 64: 157-71.

11 Fleisner P and Hofkircher W (1998) The making of the information society: driving forces, 'Leibilder' and the imperative of survival. Biosystems. 46: 201-7.

12 DeLone WH and McLean ER (1992) Information systems success: the quest for the dependent variable. Information Systems Research. 3(1): 60-95.

13 Davis FD (1989) Perceived usefulness, perceived ease of use, and user acceptance of information technology. MIS Quarterly. September: 319-40.

14 Rogers EM (1995) Diffusions of Innovations. The Free Press, New York.

15 Stamper R (1973) Information in Business and Administrative Systems. John Wiley \& Sons, New York.

16 Shannon CE and Weaver W (1949) The Mathematical Theory of Communication. University of Illinois Press, Chicago.

17 Saracevic T (1975) Relevance: a review of and framework for the thinking on the notion in information science. Journal of the American Society for Information Science. 26(6): $321-43$.

18 Michel-Verkerke MB, Schuring RW and Spil TAM (2003) Use IT or leave IT: a model to reveal user satisfaction of ICT-support in healthcare processes ex ante and ex post. In: Proceedings of the 3rd International Conference The Hospital of the Future, Association for Healthcare Technology and Management, Warwick. 
19 Saarinen T and Sääksjärvi M (1992) Process and product success in information systems development. Journal of Strategic Information Systems. 1(5): 266-77.

20 Larsen TJ (1998) Information systems innovation: a framework for research and practice. In: Information Systems Innovation and Diffusion: issues and directions, pp. 511-34. Idea Group Publishing, Hershey, PA, US.

21 Spil TAM (2002) Assessing resistance of professional users as a determinant of IT-diffusion and IT-use in healthcare. In: Proceedings of ECITE 2002, Paris.

22 Garrity EJ and Sanders GL (1998) Dimensions of information success. In: Garrity EJ and Sanders GL (eds) Information Systems Success Measurement, pp. 13-45. Idea Group Publishing, Hershey, PA, US.

23 Leavitt HJ (1965) Applied organisational change in industry: structural technological and humanistic approaches. In: March JG (ed.) Handbook of Organizations, pp. 1144-70. Rand-McNally, Chicago, IL.

24 Offenbeek Mv and Koopman $\mathrm{P}$ (1996) Interaction and decision making in project teams. In: West MA (ed.) Handbook of Work Group Psychology. John Wiley \& Sons, Chichester.

25 Mumford E (1995) Effective Systems Design and Requirements Analysis. MacMillan, London.

26 Thong JYL and Yap CS (1995) CEO characteristics, organizational characteristics and IT-adoption in small businesses. Omega. 23(4): 429-42.

27 Venkatesh V et al. (2003) User acceptance of information technology: toward a unified view. MIS Quarterly. 27(3): 425-78.

28 Schuring RW and Spil TAM (2001) Relevance as a major driver of innovation diffusion of ICT in healthcare organisations. In: Proceedings of the Hospital of the Future: 1st International Conference on Management of Healthcare and Medical Technology. University of Twente, Enschede.

29 Schuring RW and Spil TAM (2003) Relevance and micro-relevance for the professionals as determinants of IT diffusion and IT-use in healthcare. In: Grant G (ed.) ERP and Datawarehousing in Organizations: issues and challenges. IRM Press, Hershey.

30 DeLone WH and McLean ER (2002) Information systems success revisited. In: 35th Hawaii International Conference on System Sciences, Hawaii.

31 Chismar WG and Wiley-Patton S (2003) Does the extended technology acceptance model apply to physicians. In: 36th Hawaii International Conference on System Sciences, Hawaii.

32 Henry JW and Stone RW (1999) End user perception of the impacts of computer selfefficacy and outcome expectancy on job performance and patient care when using a medical information system. International Journal of Healthcare Technology and Management. 1(1/2): 103-24.

33 Spil TAM and Schuring RW (2003) Assessing requirements and resources of information systems as determinants of IT-diffusion and IT-use in healthcare. In: Proceedings of IFIP 8.6/03.

34 Pijl GJvd (1994) Measuring the strategic dimensions of the quality of information. Journal of Strategic Information Systems. 3(3): 179-90.

35 Sperber D and Wilson D (1986) RELEVANCE, Communication and Cognition. Basil Blackwell, Oxford.

36 Spil TAM and Schuring RW (2004) Requirements determine why professionals USE IT in healthcare. In: Proceedings of the 15th IRMA conference, New Orleans.

37 Ansoff I (1965) Corporate Strategy. McGraw-Hill, New York.

38 Goodstein LD and Burke WW (1991) Creating successful organizational change. Organizational Dynamics. 20(4): 5.

39 Lanning H (2001) Planning and Implementing Change in Organisations - a construct for managing change projects. Helsinki University of Technology, Espoo, Finland. 
40 Raghaven SA and Chand DR (1989) Diffusing software engineering methods. IEEE Software. July: 81-90.

41 Carey JM (ed.) (1988) Human Factors in Management Information Systems. ABLEX Publishing Corporation, New Jersey.

42 Coch L and French JRPJ (1947) Overcoming resistance to change. Human Relations; Studies Towards the Integration of Social Sciences. 1(2): 512-32.

43 Lewin K (ed.) (1952) Field Theory in Social Science, Selected Theoretical Papers. Dorwin Cartwright, London.

44 Lawrence PR (1954) How to deal with resistance to change. Harvard Business Review. 32(2): 49 .

45 Zuboff S (1982) New worlds of computer-mediated work. Harvard Business Review. March-April: 142-53.

46 Malinconico SM (1983) Hearing the resistance. Library Journal. 108(2): 111-13.

47 Folger R, Skarlicki DP and Teslu P (1999) Research notes - personality as a moderator in the relationship between fairness and retaliation. Academy of Management Journal. 42(1): 100-10.

48 Piderit SK (2000) Rethinking resistance and recognizable ambivalence: a multidimensional view of attitudes toward an organizational change. The Academy of Management Review. 25(4): 783-94.

49 Binney G and Williams C (1995) Leaning into the Future: changing the way people change organizations. N Brealy Publishing, London.

50 Kotter JP and Schlesinger LA (1979) Choosing strategies for change. Harvard Business Review. March-April: 106-13.

51 Wissema JG (1987) Angst om te veranderen? Een mythe! Van Gorcum, Assen.

52 Fuller FF (1969) Concerns of Teachers. American Educational Research Journal. 6: 207-26.

53 Schmidt R et al. (2001) Identifying software project risks: an international Delphi study. Journal of Management Information Systems. 17(4): 5-36.

54 Zmud RW (1979) Individual differences and MIS success: a review of empirical literature. Management Science. 25(10): 966-79.

55 Lapointe L, Lamothe L and Fortin JP (2002) The dynamics of IT adoption in a major change process in healthcare delivery. In: Proceedings of the 35th HICSS conference, Hawaii.

56 Scott J (1985) Weapons of the Weak: everyday forms of peasant resistance. Yale University Press, New Haven, CT.

57 Prasad P and Prasa A (2000) Stretching the iron cage: the constitution and implications of routine workplace resistance. Organizational Science. 11(4): 387-403.

58 Strebel P (1996) Why do employees resist change? Harvard Business Review. MayJune: 86-92.

59 Duck JD (1993) Managing change: the art of balancing. Harvard Business Review. November-December: 109-18.

60 Mittelstaedt RA et al. (1976) Optimal stimulation level and the adoption decision process. Journal of Consumer Research. 3: 84-94.

61 Gatignon H and Robertson TS (1989) Technology diffusion: an empirical test of competitive effects. Journal of Marketing. 53: 35-49.

62 Szmigin I and Foxal G (1998) Three forms of innovation resistance: the case of retail payment methods. Technovation. 18(6/7): 459-68.

63 Ram S and Sheth JN (1987) Bringing Innovation to Market, How to Break Corporate and Customer Barriers. Wiley, New York.

64 Markus ML (1983) Power, politics and MIS implementation. Communications of the ACM. 26(6): 430-44.

65 Dent EB and Goldberg SG (1999) Challenging 'Resistance to Change'. Journal of Applied Behavioral Science. 35(1): 25-41. 
66 Zaltman G and Duncan R (1977) Strategies for Planned Change. Wiley, New York.

67 Metselaar EE, Kolk JMvd and Wortelboer FQC (1996) Werken aan veranderingsbereidheid (in Dutch). In: Handboek effectief opleiden, pp. 135-58. Delwel, The Hague.

68 Ajzen I and Madden TJ (1986) The prediction of goal directed behavior: attitudes, intentions and perceived behavioral control. Journal of Experimental Psychology. 22: 453-74.

69 Mahmood MA et al. (2000) Variables affecting IT end-user satisfaction: a metaanalysis of the empirical literature. International Journal of Human-Computer-Studies, 52: 751-71.

70 Schuring RW and Spil TAM (2002) Explaining plateaued diffusion by combining the user-IT-success factors (USIT) and adopter categories: the case of electronic prescription systems for general practitioners. International Journal of Healthcare Technology and Management. 4: 303-18.

71 Cooper WS (1971) A definition of relevance for information retrieval. Information Storage and Retrieval. 7(1): 19-37.

72 Wilson P (1973) Situational relevance. Information Storage and Retrieval. 9(8): 457-71.

73 Ballantine J et al. (1998) Developing a 3-D model of information systems success. In: Garrity EJ and Sanders GL (eds) Information Systems Success Measurement, pp. 46-59. Idea Group Publishing, Hershey, PA, US.

74 Iivari J and Koskela E (1987) The PIOCO model for IS design. MIS Quarterly. September: 400-17.

75 Rogers EM and Scott KL (1997) The Diffusion of Innovations Model and Outreach from the National Network of Libraries of Medicine to Native American Communities. Paper prepared for the National Network of Libraries of Medicine. Pacific Northwest Region, Seattle, WA.

76 Barnard CI (1938) The Functions of the Executive. Harvard University Press, Cambridge, MA.

77 Cohen LJ (1962) The Diversity of Meaning. Methuen, London.

78 Liu K (1993) Semiotics applied to information systems development. PhD thesis. University of Twente, Enschede.

79 Spil TAM (1993) The evaluation of SISP: From a quality undergrowth to a semiotic clearing. In: Proceedings of the first ECITE Conference, Henley on Thames.

80 Wieringa RJ (2001) Requirements Engineering: frameworks for understanding. Wiley, Chichester.

81 Pressman RS (1982) Software Engineering: a practitioner's approach. McGraw-Hill, New York.

82 Mumford E (1983) Designing Human Systems for New Technology. Manchester Business School, Manchester, UK.

83 Brender J and McNair P (2001) User requirements specifications: a hierarchical structure covering strategical, tactical and operational requirements. International Journal of Medical Informatics. 64: 83-98.

84 Salmela H (1997) From information systems quality to sustainable business quality. Information and Software Technology. 39: 819-25.

85 Nykänen P (2000) Decision support systems from a health informatics perspective. In: Department of Computer and Information Sciences. University of Tampere, Tampere, Finland.

86 Hakkinen H, Turunen P and Spil TAM (2003) Information in healthcare process evaluation toolkit development. In: Proceedings of the 36th Hawaii International Conference on System Sciences, Kona, HI.

87 Yin RK (2003) Case Study Research: design and methods. Applied Social Research Series, Volume 5. Sage Publications, London.

88 Brender J (1999) Methodology for constructive assessment of IT-based systems in an organisational context. International Journal of Medical Informatics. 56: 67-86. 
89 Althuis TR and Rikken SAJJ (2000) Electronic support for general practitioners in prescribing drugs. Health information developments in the Netherlands. April: 62-6.

90 Mitchell E and Sullivan F (2001) A descriptive feast but an evaluative famine: systematic review of published articles on primary care computing during 1980-97. British Medical Journal. 322: 279-82.

91 Lagendijk PJB, Schuring RW and Spil TAM (2001) Elektronisch voorschrijf systeem. Enschede, Universiteit Twente.

\section{Appendix: Interview-protocol care provider USE IT version 14.0}

Date interview:

Name interviewer:

Name interviewee:

Job interviewee:

Organization:

P Primary process

Pl What care do you provide?

Most care providers contribute to different care processes.

In our research we make the following distinction:

- Diagnosis \%

- Investigations outside the consulting room $\%$

- Treatment \%

- Nursing \%

- Acute incidents occur: the whole day through/several times a day/several times a week

- Acute incidents dominate my work very much/somehow/a little/not

The categorization may be adjusted to the investigated care process as long as it is clear to what \% of patients or tasks the innovations applies (see REL 7)

How do you act at each of the above-mentioned tasks?

- Do you follow a fixed pattern?

- How long does a patient contact take?

- Do you use equipment?

- Do you use (human) support? If so, for whom else does this supporter work?

- Where do you perform your tasks? Could they be performed elsewhere?

- Do you always sit or stand in the same position towards the patient? (Make a sketch)

- Do you have to look up or ask after things?

- Do you have to prepare anything?

P 2 What other tasks do you have apart from providing care?

How much time or energy do these tasks take from you?

- Time \%

- Energy \% 
P 3 What exceptions or disturbances make this kind of care or the coordination of this care fail?

P 4 Do you use a care protocol or medical guideline for the care you provide?

- Do you comply with this protocol entirely or partially?

- What parts do you use, what parts don't you use?

- Does using the protocol fit with your way of working?

P 5 Who refers patients to you?

P 6 To whom do you refer patients?

P 7 What other care providers or institutions are simultaneously involved with the care for your patients?

- Do you work together?

- Or do you work 'in parallel'?

P 8 How do you experience the cooperation with other care providers in respect to the providing of the care?

P 9 With what care providers should you cooperate (more)?

- Why?

- With whom should you exchange more information?

- What information?

P 10 What do you find important in the contact with other care providers?

REQ Requirements

I $1 \quad$ What information about the patient do you need to perform your job properly? (Distinguish according to the separate tasks, mentioned in P 1 and P 2)

What information do you receive from

- The patient?

- The patient's surrounding?

- Other care providers?

- With what purpose?

- In what frequency?

What form does this information have?

- Letter (sent by post or handed over personally)

- Fax

- Email

- In paper record

- In electronic record

I 2 Does this information suffice?

- Do you experience problems?

- Do you miss information?

I 3 What information do you generate yourself when providing care?

What information do you give to:

- The patient?

- The patient's surrounding?

- Other care providers? 
- Managers?

- External parties (e.g. insurance company, government)?

What form does this information have?

- Letter (sent by post or handed over personally)

- Fax

- Email

- In paper record

- In electronic record

- Record only used for this patient group or this type of care

- Record only used by your own discipline

- Record only used in your institution

I 4 How do you appreciate the quality of the proposed (or implemented) innovation? Regarding the:

- Content

- Objectives

- Method

- Possibility to integrate it in the present situation

- Timeliness

- Correctness

I 5 Were the right end users involved with making or selecting this innovation?

REL Relevance

R 1 What do you experience, for you personally, as important in your daily work when you look at the care you provide?

R 2 What aspects in the ability to provide care, do you experience as a bottleneck or problem?

- Concerning the providing of care

- Other aspects

Are there any specific actions in the previously discussed processes that cause bottlenecks or problems?

R 3 Do you know proposals for improvement, concerning these patients, for which you would do your utmost?

R 4 How important are these proposed improvements in the chain of care in relation to other possibilities to improve aspects of your job?

- Can you name other proposals for improvement, which are more important?

- Can you name other proposals for improvement, which are less important?

R 5 In what way could the use of ICT matter to you?

- What application are you thinking of?

- For what purpose or for what situation?

R 6 What aspect of your job would you miss, if it was removed?

R 7 How important are your tasks for these patients, for you, in comparison with your tasks for other patients?

- Why are these patients so important or of so little importance for you? 
Res Resistance

A 1 To what extent are you convinced that the use of ICT is necessary to improve the provision of care?

- What experience do you have with ICT?

- How much time are you prepared to spend?

- Do you use ICT to communicate?

- How often do you use the Internet?

- How often do you use specific systems yourself?

A 2 Do you experience obstacles when implementing innovations?

- Workload

- Management support

- ICT support

- Money

- Your skills

A 3 How much time and energy do you think you can find to implement the changes that will occur when introducing innovations and ICT in this kind of care?

A 4 Do your colleagues or managers stimulate you to participate in changes?

A 5 Can you name other innovation projects this organization is working on? Are these projects equally important (or more or less important)?

Res Resources

M 1 What ICT facilities do you have at your disposal at your workplace?

- Hardware

- Software

- For communication

- Data

M 2 Which of these ICT facilities do you use when providing care?

- Hardware

- Software

- For communication

- Data

M 3 Is the technical support sufficient to guarantee the quality of the system?

- Reliability

- Availability

- Security

- Privacy

M 4 Do you think you will have support to implement changes?

- Time

- Money

- Training

- Management support

C Concluding questions

C 1 Is there anything you would like to add?

C 2 May we contact you to think with us in the development of a ICT application?

Copyright 2004, Schuring \& Spil, only use with permission from the authors. 